Research Article

\title{
Dynamic Response and Parametric Studies of Elliptical Blast-Resistant Door with the Combined Structure for Large Vacuum Explosion Containers
}

\author{
Saiwei Cheng $\mathbb{D},{ }^{1}$ Xiaojie Li $\mathbb{D}^{1,2}$ Yang Wang $\mathbb{D}^{1},{ }^{1}$ Yuxin Wang $\mathbb{D}^{1},{ }^{1}$ and Honghao Yan $\mathbb{D}^{1}$ \\ ${ }^{1}$ Department of Engineering Mechanics, Dalian University of Technology, Dalian 116024, China \\ ${ }^{2}$ State Key Laboratory of Structural Analysis for Industrial Equipment, Dalian University of Technology, Dalian 116024, China
}

Correspondence should be addressed to Xiaojie Li; robinli@dlut.edu.cn

Received 12 July 2021; Revised 2 September 2021; Accepted 21 October 2021; Published 3 November 2021

Academic Editor: Bing Zhang

Copyright ( $) 2021$ Saiwei Cheng et al. This is an open access article distributed under the Creative Commons Attribution License, which permits unrestricted use, distribution, and reproduction in any medium, provided the original work is properly cited.

In recent years, with the improvement of environmental protection requirements year by year and the continuous expansion of explosive working scale, higher standards have been put forward for explosive working. It is hoped that the sphere of influence of the explosion can be limited to a minimal range. The explosion vessel is driven by such demand. As the explosion vessel's key component, studying the blast-resistant door in depth is of great significance. This paper introduces a new elliptical blast-resistant door with the combined structure (EBD), mainly welded with an elliptical panel, arc support plate, and triangle support plate. The finite element program AUTODYN was used to calculate the explosion load, and LS-DYNA was used to calculate the blastresistant door's dynamic response. The calculation results show that the newly proposed EBD's blast-resistance capacity is better than that of the traditional structure. To further study the factors that affect the dynamic response of the EBD, a parametric study was carried out on the EBD, mainly analyzing the influence of the vacuum degree in the explosion vessel, the number of explosives, and the diameter ratio of the EBD. The parametric calculation results show that reducing the vacuum degree in the explosion vessel and the number of explosives during explosion working can improve the blast-resistance capacity of the EBD. Based on the analysis of the dynamic response of four kinds of EBD with different diameter ratios under $0.2 \mathrm{~atm}$ explosion load, the optimal diameter ratio of the EBD is given.

\section{Introduction}

Explosive working is a material processing method that relies on explosive detonation's high-speed and high-pressure impact to carry out plastic forming, surface modification, and metallurgical bonds between metals [1]. The common explosive working methods include explosive strengthening [2-4], explosive welding [5-7], explosive compaction $[8,9]$, explosive cutting [10-12], detonation synthesis $[13,14]$, and so on. Explosion working is often carried out outdoors. However, the strong shock wave, noise, harmful gas, and dust produced by the explosion will greatly impact the surrounding environment [15]. Nowadays, environmental problems are becoming more and more serious. Besides, with the increasing production and explosive quantity of explosive working, the single explosive quantity of explosive working is close to 1 ton. The traditional outdoor bare explosion production mode can no longer meet the needs of industrial production. The vacuum explosion vessel can just solve these problems. At the same time, the blast-resistant door is a critical component of the vacuum explosion vessel. Its primary function is to seal the container and enter and exit the materials (i.e., meet large vehicles and machinery requirements to enter and exit the explosion vessel). The antiexplosion ability of the blast-resistant door on the explosion vessel directly affects the whole explosion vessel's antiexplosion ability. Therefore, it is crucial to study the blast-resistant door of a large explosion vessel.

Blast-resistant doors are widely used in defense engineering, civil air-defense construction, petrochemical engineering, mining industry, and other fields [16-18]. The 
research of traditional blast-resistant doors is mainly from two aspects of structure and material. In the research of blast-resistant door structures, traditional blast-resistant doors are mostly made of steel, with beam slab structure [19]. The beam-slab blast-resistant door is mainly composed of panels and ribbed beams. The rib beam is arranged on the bottom of the face slab by crossing the longitudinal rib and the transverse rib. The blast-resistant door mainly bears the combined action of membrane stress and bending stress subjected to blast load [18]. There are relatively few researches on beam-slab blast-resistant doors in published materials at present. However, beam-slab blast-resistant doors can be regarded as a combination of stiffened plates/ shells. Early studies on stiffened plates/shells indicate that stiffening is an effective method to improve the structure's flexural rigidity without increasing weight [20]. Some scholars have also studied the direction (longitudinal and transverse), position, shape, size, and a number of the stiffeners and found that the above factors affect stiffened plates' dynamic characteristics [21-24]. Although the application scope of the beam-slab blast-resistant door is broad, it is mostly used in protection engineering with a low resistance level.

In the blast-resistant door's material research, the beamslab blast-resistant door is usually filled with concrete [18] or foam aluminum [25] to improve the blast-resistance capacity. With the continuous development of new materials and technology, various new composite materials have been used to research blast-resistant doors. Zhao et al. [26, 27] studied the blast-resistance capacity of sheet molding compound (SMC) blast-resistant door and basalt fiber reinforced polymers and sheet molding compound (BFRPSMC) blast-resistant door. The research results show that SMC and BFRP-SMC materials can significantly improve the blast-resistant door's flexural rigidity and bearing capacity. They are one of the alternative materials for lightweight blast-resistant door structures. Although the new material can improve the blast-resistant door's blast-resistance ability, it does not consider its fatigue and durability.

The traditional blast-resistant door only considers the blastresistance ability once. It allows the blast-resistant door to produce large deformation and even a certain degree of damage. The blast-resistant door to be studied in this article is different from the traditional blast-resistant door. It is the critical component of a large explosion vessel. It needs to bear long-term and repeated explosive load in the process of explosive working. Accordingly, the deformation of the blastresistant door should always be kept in the elastic range. Under the actual production conditions of explosive working, the blast-resistant door should be designed to manufacture, install, and maintain expediently and should be at low cost and good fatigue resistance. To this end, we designed a steel elliptical blast-resistant door with a combined structure (EBD). Then, the EBD is compared with the same mass flat blast-resistant door (FBD) and the reinforced flat blast-resistant door (RFBD). The numerical results show that the blast-resistance capacity of the EBD designed in this paper is better than that of the FBD and the RFBD. Besides, we also have carried out a parametric study on the EBD and analyzed the factors affecting the blast- resistance capacity of the $\mathrm{EBD}$ one by one, including the vacuum degree of the explosion vessel, the number of explosives, and the diameter ratio of the EBD.

\section{Explosive Load}

The explosive load in the confined space is different from that in the free field [28]. Due to the container wall restriction, the confined space's explosion shock wave has an apparent reflection phenomenon [29]. The back and forth reflection of the shock wave in the explosion vessel can significantly enhance the explosive load's peak pressure and impulse, which can cause more significant damage to the vessel and its attached structures [30]. However, considering that the explosion shock wave is easily affected by the environmental conditions $[31,32]$, the shock wave's peak pressure and impulse can be reduced by reducing the ambient pressure [33]. In this paper, the blast-resistant door on the explosion vessel with a volume of $1,600 \mathrm{~m}^{3}$ is studied. The explosive vessel's designed maximum working charge is $600 \mathrm{~kg}$ ANFO (ammonium-nitrate/fuel-oil) explosive. The vessel is vacuumized in each explosion process to reduce the vessel's initial ambient pressure.

2.1. Computational Model. It is assumed that the blast-resistant door works under extreme conditions. At this time, the working charge of the explosive container is $600 \mathrm{~kg}$ ANFO explosive. The distance between the center of the explosive and the blast-resistant door is $7.2557 \mathrm{~m}$, which is the position of gauge 1 in Figure 1. The scaled distance is given as follows:

$$
\bar{R}=\frac{R}{\sqrt[3]{W}}=\frac{7.2557 \mathrm{~m}}{\sqrt[3]{600 \mathrm{~kg}}} \cong 0.86 \mathrm{~m} / \mathrm{kg}^{1 / 3},
$$

where $\bar{R}$ is the scaled distance in $\mathrm{m} / \mathrm{kg}^{1 / 3}, R$ is the distance from the center of the explosive to the blast-resistant door in $\mathrm{m}$, and $w$ is the mass of ANFO explosive in $\mathrm{kg}$.

In the calculation, ANFO uses the JWL (Jones-Wilkins-Lee) equation of state.

$$
P=A\left(1-\frac{\omega \eta}{R_{1}}\right) e^{-R_{1} / \eta}+B\left(1-\frac{\omega \eta}{R_{2}}\right) e^{-R_{1} / \eta}+\omega \rho e,
$$

Since both the explosive vessel and the explosive are spherical, the numerical calculation model can be simplified to a spherically symmetric model. A two-dimensional axisymmetric wedge model similar to one-dimensional spherical symmetry is used for calculation, as shown in Figure 1. According to reference [34], it is sufficient to divide the element size into $5 \mathrm{~mm}$ for calculating shock wave overpressure. The model adopts the 2D multimaterial Euler algorithm of the AUTODYN-19 program. The explosive and air are filled into the wedge mesh. A rigid boundary is set at the wedge model's wide end to simulate the closed vessel's characteristics:where $P$ is the pressure, $\rho_{0}$ is the reference density, $\rho$ is the density of detonation products, here $\eta=\rho / \rho_{0}, e$ is the internal energy per unit mass of explosive, and $A, B, R_{1}, R_{2}$, and $\omega$ are the parameters of the JWL equation of state. The material parameters of ANFO explosives are provided by the AUTODYN program in Table 1. 


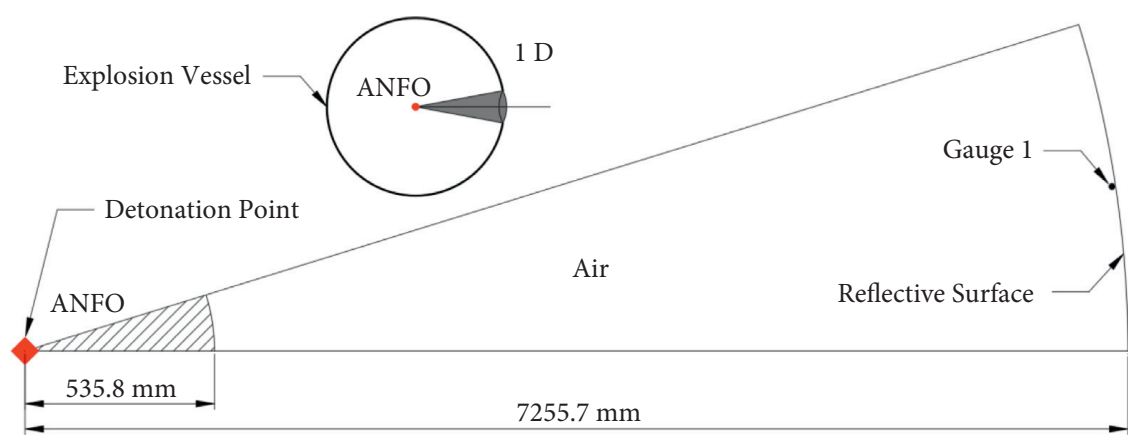

Figure 1: The calculation model of explosive load.

TABLE 1: Material parameters of ANFO explosive [35].

\begin{tabular}{lcccccccc}
\hline$\rho\left(\mathrm{kg} / \mathrm{m}^{3}\right)$ & $D_{C J}(\mathrm{~m} / \mathrm{s})$ & $P_{C J}(\mathrm{GPa})$ & $E_{C J}\left(\mathrm{~J} / \mathrm{m}^{3}\right)$ & $A(\mathrm{GPa})$ & $B(\mathrm{GPa})$ & $R_{1}$ & $R_{2}$ & $\omega$ \\
\hline 931 & 4160 & 5.15 & $2.484 \times 10^{9}$ & 49.46 & 1.891 & 3.907 & 1.118 & $1 / 3$ \\
\hline
\end{tabular}

The ideal gas equation of state is used for air as follows:

$$
P=(\gamma-1) \rho e,
$$

where $P$ is the pressure, $\gamma$ is the adiabatic exponent, $\rho$ is the air density, and $e$ is the air's specific internal energy. The material parameters of air are shown in Table 2 .

2.2. Vacuum Setting. To reduce the pressure in the explosive vessel during the actual production process, the vacuum pump was used to vacuum the vessel until the vessel's pressure dropped to $0.2 \mathrm{~atm}$. In the numerical calculation, it can be seen from equation (3) that the air environment under different vacuum conditions can be approximately simulated by changing the density and specific internal energy of air in the equation of state.

Assuming that air is an ideal gas, then

$$
d e=c_{v} d T
$$

where $e$ is internal energy per unit mass, $c_{v}$ is the specific heat at constant volume, and $T$ is temperature. It can be seen from equation (4) that the internal energy of the ideal gas is only a function of temperature. If the initial temperature is kept constant, the internal energy of the air must remain constant. Combined with equation (3), the pressure is a single-valued function of density under the condition of keeping the initial temperature constant. Therefore, the initial density of air at $0.2 \mathrm{~atm}$ can be expressed as follows:

$$
\rho_{0.2}=\frac{P_{0.2}}{P_{0}} \rho_{0}
$$

where $\rho_{0}$ is the air density under standard conditions, taking $1.225 \mathrm{~kg} / \mathrm{m}^{3} ; P_{0}$ is the air pressure under standard conditions, taking $1.013 \times 105 \mathrm{~Pa} ; P_{0.2}$ is the air pressure when the vacuum degree is $0.2 \mathrm{~atm}$; and $\rho_{0.2}$ is the air density when the vacuum degree is $0.2 \mathrm{~atm}$. According to equation (5), $\rho_{0.2}=0.245 \mathrm{~kg} / \mathrm{m}^{3}$.
TABLE 2: Material parameters of air under standard conditions.

\begin{tabular}{lcccc}
\hline$\rho\left(\mathrm{kg} / \mathrm{m}^{3}\right)$ & $\gamma$ & $e(\mathrm{~J} / \mathrm{kg})$ & $T(\mathrm{~K})$ & $c(\mathrm{~J} / \mathrm{kg} \cdot \mathrm{K})$ \\
\hline 1.225 & 1.4 & $2.068 \times 10^{5}$ & 288 & 717.6 \\
\hline
\end{tabular}

2.3. Explosive Load at $0.2 \mathrm{~atm}$. In Figure 1, gauge 1 represents the position of the blast-resistant door from the center of the explosive. The explosive load at $0.2 \mathrm{~atm}$ at gauge 1 obtained by numerical calculation is shown in Figure 2(a). The red horizontal line indicates the residual gas pressure after explosive detonation. It can be seen from Figure 2(a) that the explosive load in the confined space fluctuates up and down along a particular value after multiple reflections. The researchers divided the internal blast loading into two stages: the shock wave reflection phase and the long quasistatic phase [36]. When the explosion shock wave is reflected inside the vessel, the latter shock wave peak overpressure and impulse are always smaller than those of the former. The final shock wave will slowly decay to the quasi-static pressure. However, considering the influence of charge shape and initiation position on shock waves during explosive working, the actual detonation process is not as utterly symmetrical as the ideal conditions. In this way, the regular reflection in Figure 2(a) cannot be generated. The internal blast loading may consist of only the first pulse wave and quasi-static pulse. Therefore, the internal blast loading is simplified in this paper. The first shock wave of the internal blast loading is taken as the input load to study the blastresistant door's dynamic response, as shown in Figure 2(b). Here, the influence of quasi-static pressure on the dynamic response of the blast-resistant door is ignored. In the followup research, we will further study the influence of quasistatic pressure on the blast-resistant door's dynamic response.

2.4. Verification of the Decoupling Algorithm. Because of the large volume of the explosion vessel, the complete numerical 


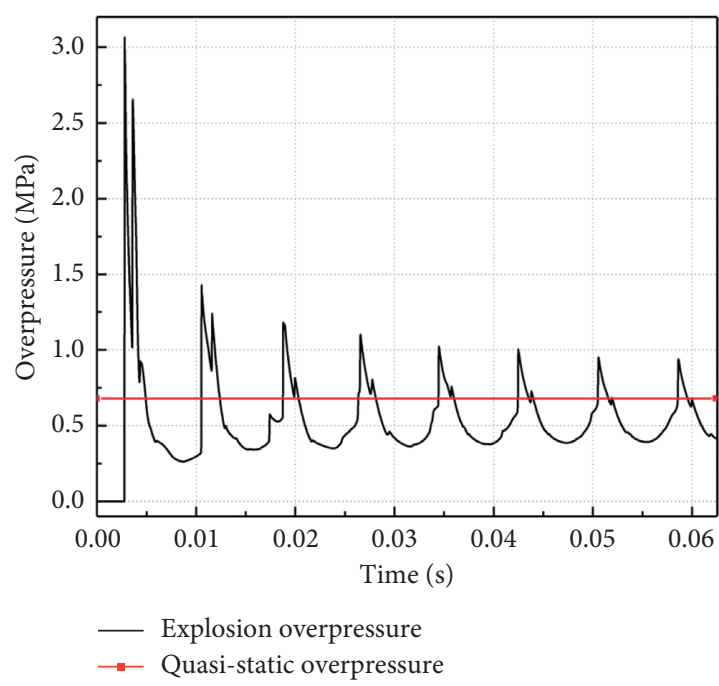

(a)

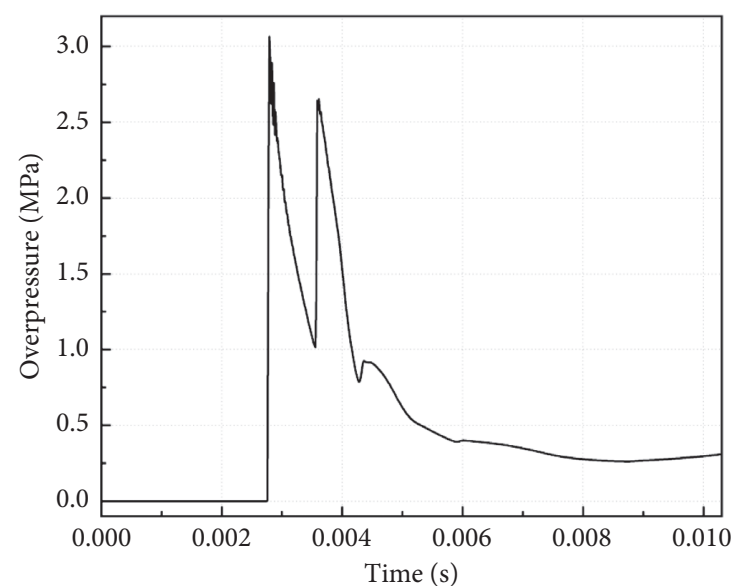

(b)

Figure 2: The time history curve of reflected overpressure at gauge 1: (a) explosive load at 0.2 atm and (b) simplified explosive load.

model will involve explosives, air, explosion vessels, and blast-resistant doors. The calculation model is complicated and time-consuming. To simplify the calculation, this paper uses the decoupling method to calculate the explosive load. The calculated explosive load is then applied to the blast-resistant door to calculate the blastresistant door's dynamic response. We assume that the boundary is rigid when calculating the explosive load. However, the actual explosion vessel and blast-resistant door are deformable bodies, different from the rigid boundary. The shock wave pressure disturbance of the blast-resistant door can be calculated by the shock wave acoustic theory as follows:

$$
p=\rho c u \text {. }
$$

The yield velocity of steel is calculated as follows:

$$
u_{Y}=\frac{\sigma_{Y}}{\rho_{0} c_{0}} .
$$

The yield strength $\sigma_{Y}$ of the steel is assumed to be $400 \mathrm{MPa}$. The wave impedance $\rho_{0} c_{0}$ is $4 \times 107 \mathrm{~N} \cdot \mathrm{s} / \mathrm{m}^{3}$. Then the yield velocity $u_{Y}$ of the corresponding steel is $10 \mathrm{~m} / \mathrm{s}$. At this point, the disturbed air velocity $u$ near the blast-resistant door is also $10 \mathrm{~m} / \mathrm{s}$. By substituting the air density $\rho=1.225 \mathrm{~kg} / \mathrm{m}^{3}$ and the sound velocity $c=340 \mathrm{~m} / \mathrm{s}$ into equation (6), the disturbance pressure $p$ is $4165 \mathrm{~Pa}$. It can be seen from Figure 2 that the peak overpressure $\Delta p$ of the shock wave is $3.07 \times 106 \mathrm{~Pa}$.

$$
\frac{p}{\Delta p}=\frac{4165 \mathrm{~Pa}}{3.07 \times 10^{6} \mathrm{~Pa}} \times 100 \%=0.14 \%
$$

The calculation shows that the blast-resistant door's deformation has very little disturbance to the shock wave overpressure. The blast-resistant door can be simplified as a rigid boundary when calculating the explosive load. Therefore, the decoupling algorithm used in this paper is reasonable.

\section{Numerical Calculation of the Blast- Resistant Door}

In today's world, the rapid improvement of computer hardware performance has promoted numerical computation. The emergence of various commercial finite element software reduces the difficulty of using numerical methods to solve problems. Nowadays, the finite element method seems to have become a new calculation "standard." Many scholars compare the theoretical solutions with the finite element calculation results to verify the new theory's effectiveness [37-40]. Therefore, this paper uses the commercial finite element software LS-DYNA to calculate the blast-resistant door's dynamic response. LS-DYNA software is widely used to analyze structural impact problems because of its powerful nonlinear calculation ability and numerous material models. Many examples show that LS-DYNA is reliable in calculating structural response with damage and considerable deformation [17, 41-43].

3.1. Structural Style. In this paper, the elliptical blast-resistant door with the combined structure is referred to as EBD. The flat blast-resistant door is referred to as FBD. The reinforced flat blast-resistant door is referred to as RFBD. To compare the blast-resistance capacity of the EBD proposed in this paper, we compare the EBD with the common FBD and RFBD. The mass between different blast-resistant doors is equal by adjusting each part of the blast-resistant door's thickness in the research process. The FBD is made of steel plate with a thickness of $74.7 \mathrm{~mm}$, as shown in Figure 3 . According to the number and arrangement of stiffeners, there are five structural forms of RFBD, as shown in Figure 4. The length, height, and thickness of the RFBD's stiffener are $4,000 \mathrm{~mm}, 150 \mathrm{~mm}$, and $40 \mathrm{~mm}$, respectively. Its structural form is shown in Figure 4(f). The EBD is composed of an elliptical panel; four arc support plates; and four triangle support plates, with a thickness of $50 \mathrm{~mm}$, as shown in 


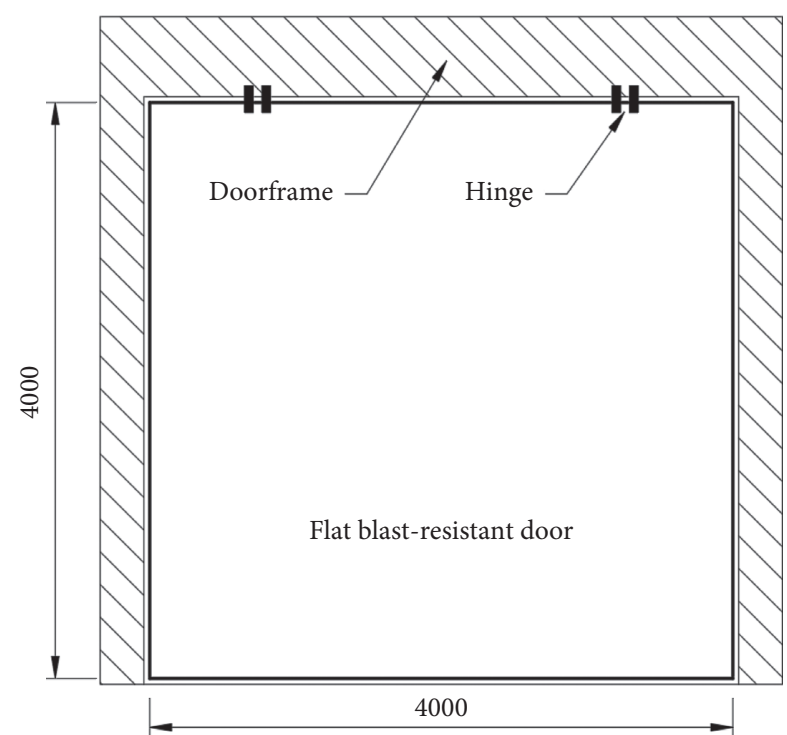

Figure 3: Flat blast-resistant door (FBD; unit: $\mathrm{mm}$ ).

Figure 5. The projection dimensions of the blast-resistant doors studied in this paper are all 4,000 $\mathrm{mm} \times 4,000 \mathrm{~mm}$, and their specifications are shown in Table 3.

3.2. Material Model. The blast-resistant door is made of Q355 high-strength, low-alloy structural steel. The explosive load acting on the blast-resistant door is relatively short, about $10 \mathrm{~ms}$ (see Figure 2(b)). The deformation of the blastresistant door is faster under severe dynamic load. Previous experimental studies have shown that the dynamic strength of steel is significantly higher than that of static strength, that is, the steel will show a hardening phenomenon under highspeed impact conditions. Therefore, the Johnson-Cook constitutive model in LS-DYNA is used to simulate the blastresistant door's dynamic behavior. The Johnson-Cook model comprehensively considers the effects of strain, strain rate, strain history, and temperature on the flow stress and multiplies and couples the parameters together. It is very suitable for the dynamic response analysis of structures under explosive load [45].

$$
\sigma_{y}=\left(A+B \bar{\varepsilon}_{p}^{n}\right)\left(1+C \ln \dot{\varepsilon}^{*}\right)\left(1-T^{* m}\right),
$$

where $\sigma_{y}$ is the von Mises flow stress; $A, B, \mathrm{C}, n$, and $m$ are the material parameters; $\bar{\varepsilon}_{p}$ is the effective plastic strain; $\dot{\varepsilon}^{*}=$ $\dot{\mathcal{\varepsilon}} / \dot{\varepsilon}_{0}$ is the normalized effective plastic strain rate; $\dot{\varepsilon}$ is the plastic strain rate; $\dot{\varepsilon}_{0}$ is the quasi-threshold strain rate; $T^{*}=$ $T-T_{\text {room }} / T_{\text {melt }}-T_{\text {room }}$ is the dimensionless temperature; and $T, T_{\text {room }}$, and $T_{\text {melt }}$ are the temperature during the deformation of the material, room temperature, and melt temperature, respectively. The Q355 material parameters used in the numerical calculations are shown in Table 4.

3.3. Element, Mesh, and Boundary Condition. Since the dimension of the thickness direction of the blast-resistant door is much smaller than that of the other two directions, the Belytschko-Tsay shell element can be used to simulate the dynamic response of the blast-resistant door. The finite element model of the EBD is shown in Figure 6. In practical use, the blast-resistant door is fixed on the door frame by hinges and bolts. Therefore, in the numerical calculation, to approximate simulate the actual boundary conditions, the keyword $*$ BOUNDARY_SPC can be used to constrain the degrees of freedom of UX, UY, and UZ around the blastresistant door.

The accuracy of numerical calculation depends on the size of the finite element mesh. The computation result obtained by the sparse grid has a large error. Although the calculation accuracy of the dense grid is high, the calculation efficiency is low. Finite element calculation needs to find a balance between accuracy and efficiency. Therefore, to study the grid's influence, we analyze the EBD and take the grid size of $100 \mathrm{~mm}, 50 \mathrm{~mm}, 10 \mathrm{~mm}$, and $5 \mathrm{~mm}$. The displacement calculation results of the mid-span node of the blast-resistant door are shown in Figure 7.

It can be seen from Figure 7 that the convergence of the calculation results is good when the grid size is reduced to $10 \mathrm{~mm}$. When the grid size is further reduced to $5 \mathrm{~mm}$, the calculation results of the mid-span displacement of the blastresistant door are almost the same as those of the $10 \mathrm{~mm}$ grid, but the cost of computer time has increased by 12 times. From the perspective of deformation shape, the blast-resistant door mainly bears in-plane bending under the explosive load. The Belytschko-Tsay shell element adopts the single-point integration algorithm. The finer grid can more accurately simulate the bending behavior of the blast-resistant door. Hence, after comprehensively considering the accuracy and efficiency, this paper adopts a $10 \mathrm{~mm}$ grid to calculate the blast-resistant door's dynamic response.

3.4. Results and Discussion. To determine the structure's dynamic response under explosive load, it is necessary to calculate its displacement, stress, and strain. Figure 8 shows the displacement contour of the EBD and the RFBD2. The displacement contours of other blast-resistant doors are similar to Figure 8, which are not given here. Figure 9 shows the peak displacement in the mid-span of all blast-resistant doors. It can be seen from Figure 9 and Table 5 that the peak displacement of the RFBD is smaller than that of the FBD. It indicates that the reinforcement can improve the blast-resistant door's blast-resistance capacity, but the improvement is relatively small compared with the EBD. Except for RFBD3, the peak displacement of other RFBD decreases gradually with the increase of the number of stiffening ribs. The reason is that the stiffening rib bears part of the explosive load, which changes the mechanical characteristics of the blast-resistant door, thus improving its overall flexural rigidity. The peak displacement response of the RFBD3 is smaller than that of the RFBD4. The reason is that the midspan measuring point of the RFBD3 is just at the longitudinal rib and the transverse rib intersection. When the stiffening ribs are arranged as RFBD5, the peak displacement of the RFBD is the smallest, which is $66.8 \mathrm{~mm}$ and $11.8 \%$ less than that of the FBD. The EBD peak displacement is $5.1 \mathrm{~mm}$, 93.3\% less than that of the FBD, and $92.4 \%$ less than that of 


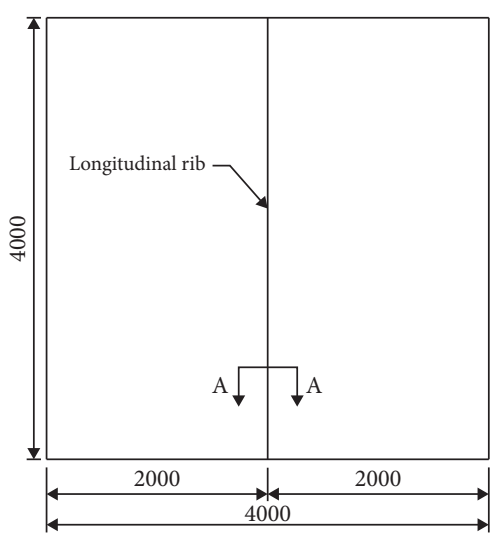

(a)

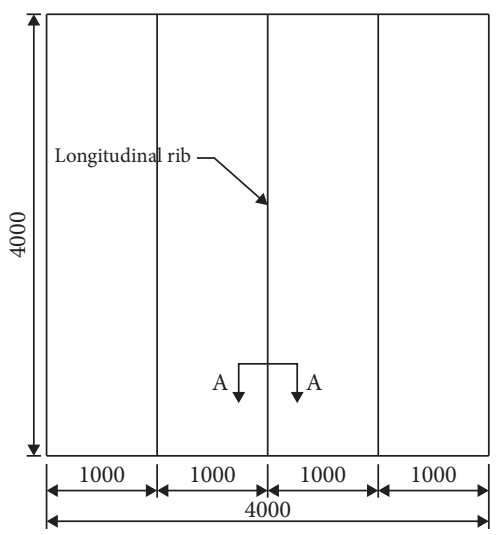

(d)

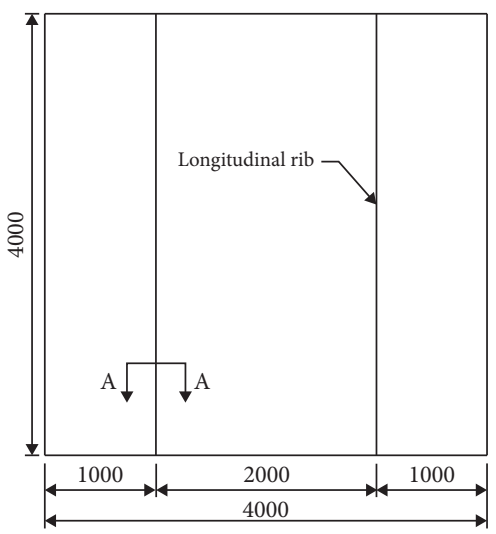

(b)

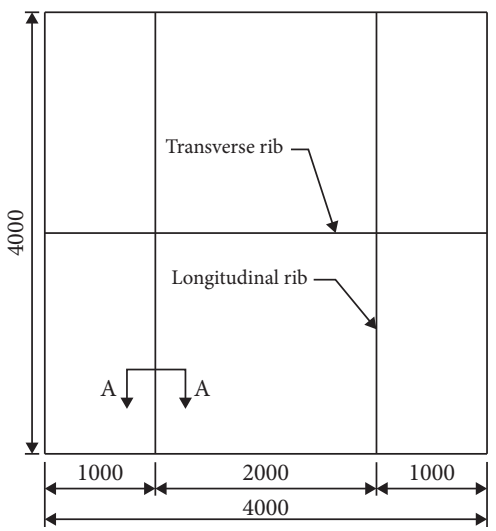

(e)

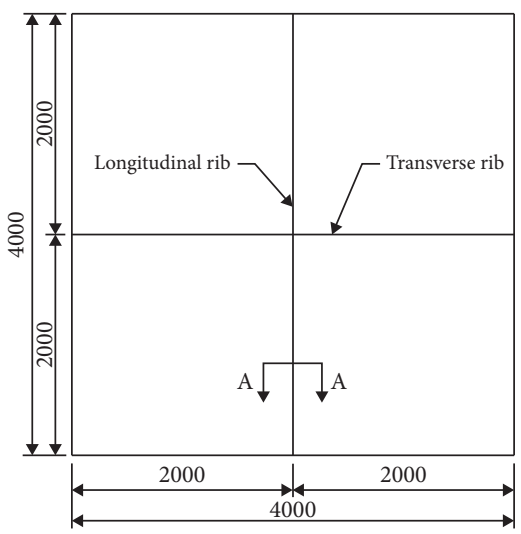

(c)

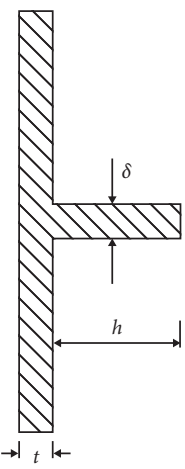

(f)

FIGURE 4: Reinforced flat blast-resistant door (RFBD; unit: mm): (a) one longitudinal rib (RFBD1), (b) two longitudinal ribs (RFBD2), (c) one longitudinal rib and one transverse rib (RFBD3), (d) three longitudinal ribs (RFBD4), (e) two longitudinal ribs and one transverse rib (RFBD5), and (f) section A-A.

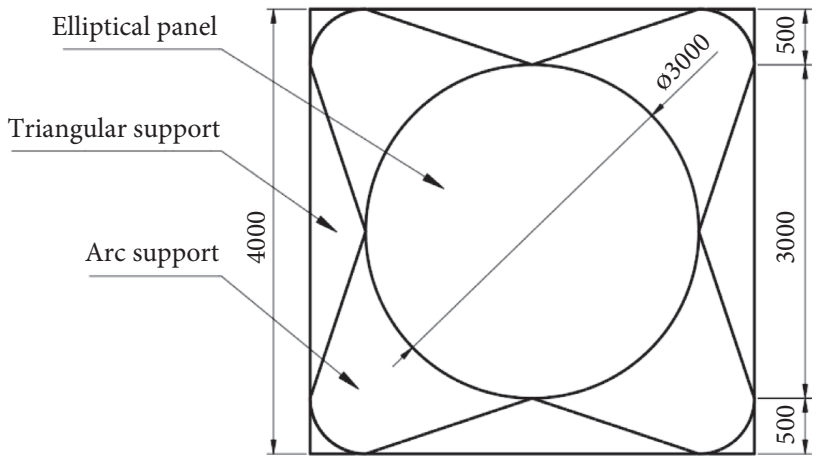

(a)

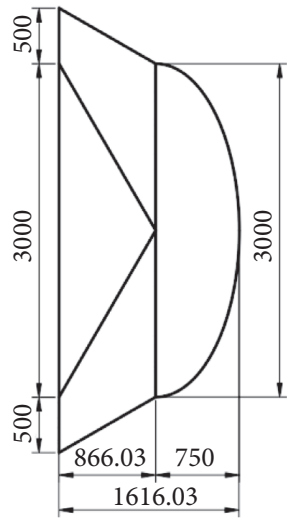

(b)

FIGURE 5: Elliptical blast-resistant door with the combined structure (EBD; unit: $\mathrm{mm}$ ): (a) front view and (b) side view.

the RFBD5. The time history curve of mid-span displacement of the blast-resistant door is shown in Figure 10. It can be seen from Figure 10 that the vibration period of the EBD is much smaller than that of the FBD and the RFBD. The smaller the vibration period of the blast-resistant door with the same mass, the greater the structure's rigidity and the stronger the ability to resist deformation, that is, the better the blast-resistance capacity. Therefore, the EBD proposed in this paper has better blast-resistance capacity.

Figures 11-13 show the maximum von Mises stress and effective plastic strain of the blast-resistant doors with different structural forms under explosive load. In Figure 11, 
Table 3: Parameters of different blast-resistant doors.

\begin{tabular}{lccc}
\hline Type & Longitudinal rib & Transverse rib & Thickness $t(\mathrm{~mm})$ \\
\hline FBD & - & - & 74.7 \\
RFBD1 & 1 & 0 & 73.2 \\
RFBD2 & 2 & 0 & 71.7 \\
RFBD3 & 1 & 1 & 71.7 \\
RFBD4 & 3 & 0 & 70.2 \\
RFBD5 & 2 & 1 & 70.2 \\
EBD & - & - & 50.0 \\
\hline
\end{tabular}

TABLE 4: Material parameters of the Q355 steel [44].

\begin{tabular}{lcccccccccc}
\hline$\rho\left(\mathrm{kg} / \mathrm{m}^{3}\right)$ & $E(\mathrm{GPa})$ & $v$ & $A(\mathrm{MPa})$ & $B(\mathrm{MPa})$ & $n$ & $m$ & $C$ & $\dot{\varepsilon}_{0}$ & $T_{\text {room }}(\mathrm{K})$ & $T_{\text {melt }}(\mathrm{K})$ \\
\hline 7,850 & 206 & 0.28 & 339.45 & 620 & 0.403 & 0.659 & 0.02 & $1.333 \times 10^{-3}$ & 293 & 1,800 \\
\hline
\end{tabular}

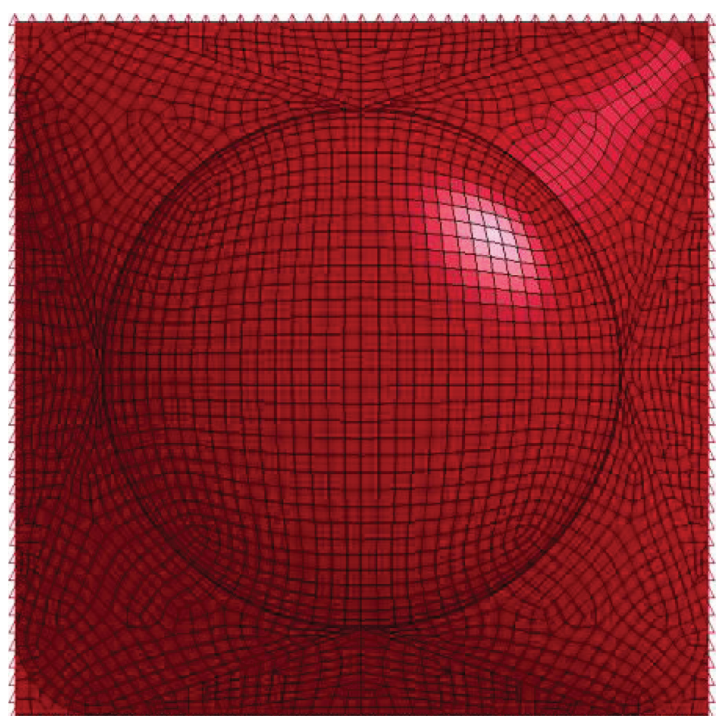

FIgURE 6: Finite element model with boundary conditions (mesh size: $100 \mathrm{~mm}$ ).

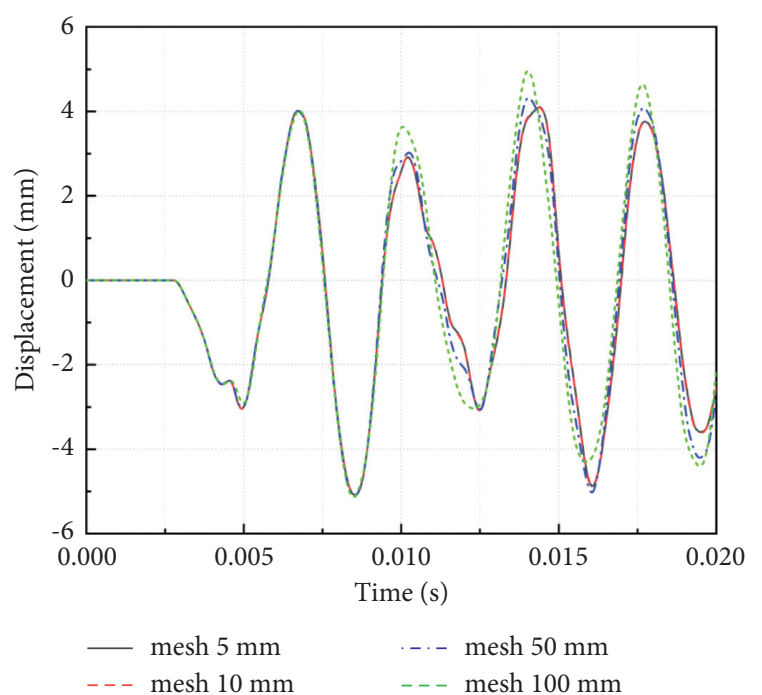

FIGURE 7: Displacement time history curves of different mesh sizes. the stress distribution of the FBD is not uniform, but a sizeable high-stress area appears in the central area. The FBD yields from the center and extends to the surroundings with the maximum effective plastic strain of $0.14 \%$. The von Mises stress contour and effective plastic strain contour of the RFBD5 with the smallest mid-span peak displacement are shown in Figure 12. The maximum von Mises stress of the RFBD5 occurs in the stiffening ribs with a value of 454.2 $\mathrm{MPa}$, which indicates that the stiffening ribs are subjected to a large load during the blast loading and resulted in a large plastic deformation in this region with maximum effective plastic deformation of $0.52 \%$. In Figure 13, the maximum stress occurs at the joint between the elliptical panel and the arc support plate, where the maximum von Mises stress is 437.6 MPa. None of the von Mises stresses in the rest of the EBD exceed $270 \mathrm{MPa}$, much less than the static yield strength of Q355 steel. The reason is that the horizontal reaction force is generated at the joint between the elliptical panel and the arc support plate under explosive load. This force and the vertical force together cause high stress at the joint (here is an orthogonal decomposition of the force at the joint. In fact, the joint is subjected to the resultant force). In the subsequent optimization design, the internal force at the joint between the elliptical panel and the arc support plate can be reduced by providing stiffening ribs or changing the elliptical minor axis's diameter. As shown in Figure 13 and Table 5, the maximum effective strain of the EBD occurs at the maximum stress of the blast-resistant door, with a magnitude of $0.11 \%$. It indicates that the plastic deformation occurring here is extremely small. Except for the joint between the elliptical panel and the arc support plate, the rest of the EBD is in the state of perfect elasticity deformation. Overall, the maximum von Mises stress and effective plastic strain of the EBD are less than those of the FBD and the RFBD.

From the above analysis, it can be seen that the stress distribution of the EBD proposed in this paper is relatively uniform. Moreover, the von Mises stress in most areas of the EBD is much less than the static yield strength of the blastresistant door material. It leaves greater safety redundancy for the blast-resistant door design. Under the same $0.2 \mathrm{~atm}$ vacuum explosive load, the displacement response of the 


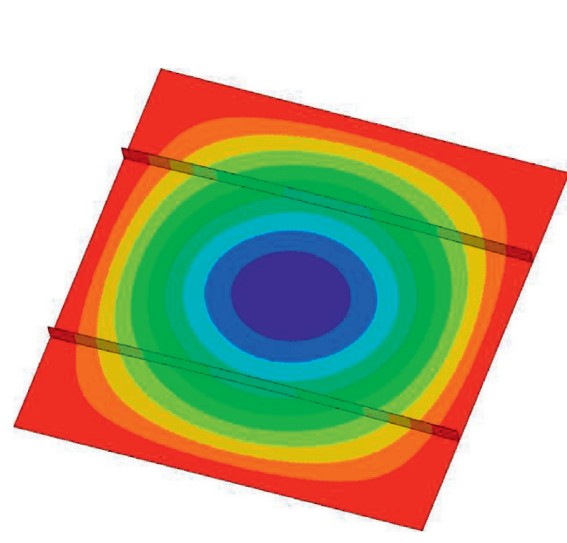

(a)

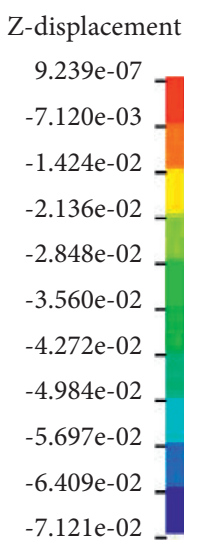

FIgURE 8: Displacement contour of the blast-resistant door: (a) RFBD2 and (b) EBD.

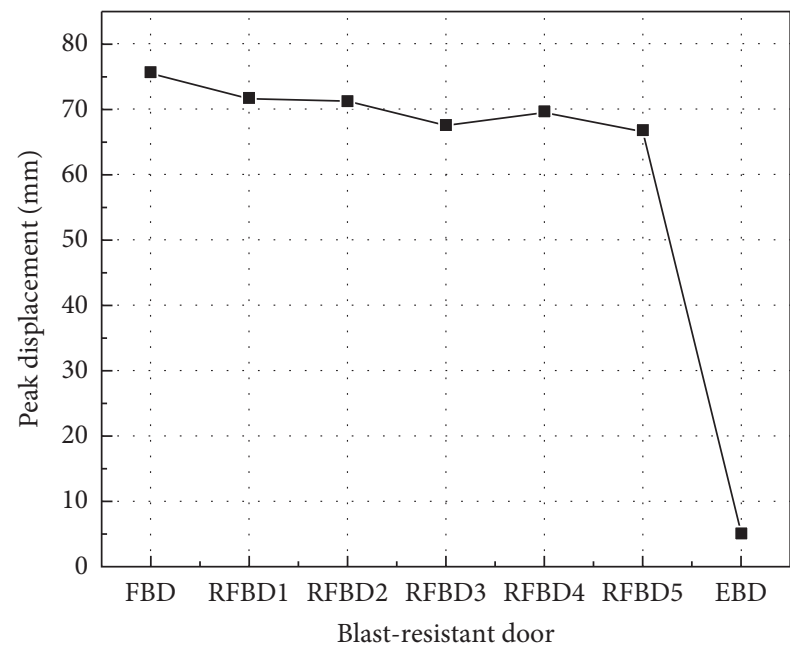

Figure 9: Peak displacement of different blast-resistant doors.

EBD is smaller than that of the FBD and the RFBD. It indicates that the EBD has a better blast-resistance capacity. However, the careful analysis also found a slight plastic deformation at the joint between the elliptical panel and the arc support plate of the EBD, so it can be further optimized to achieve better blast resistance performance.

\section{Parametric Study of the EBD}

The dynamic response of the EBD is influenced by three factors: the vacuum degree of the explosive vessel, the number of explosives during the explosion working, and the diameter ratio of the EBD. In this section; these factors are analyzed one by one to achieve the optimum blast-resistant structure for the EBD. The EBD's loading mode, material model, element type, mesh size, and boundary conditions are similar to those in the previous section.

4.1. Effect of Vacuum Degree. The internal blast loading under different vacuum degrees is shown in Figure 14. It can be seen from Figure 14 that there are two distinct peaks for each explosive load pulse. The first peak is an air shock wave formed by the detonation product compressed air. The second peak is a shock wave formed by the expansion of the detonation product. With the decrease of the vacuum degree inside the explosion vessel, the first peak of the internal blast loading decreases gradually. In contrast, the second peak caused by the detonation product increases gradually. Overall, the smaller the vacuum degree is, the faster the decay of the internal blast loading is, that is, the smaller the slope of the load impulse curve in Figure 14. The explosive load under different vacuum degrees calculated in Figure 14 is applied as an input load to act on the EBD. The calculated dynamic response of the EBD is given in Table 6 . The time history curve of the mid-span displacement is illustrated in Figure 15. The 1 and 2 marked in Figure 15 represent the first and second peaks of the displacement response, respectively.

As can be seen in Figure 15 and Table 6, except for the second peak of the displacement response at $0.2 \mathrm{~atm}$, the peak displacement, the maximum von Mises stress, and the maximum effective plastic strain of the EBD gradually decrease with the decrease of the vacuum degree inside the explosion vessel. When the vacuum degree is $0.2 \mathrm{~atm}$, the second peak displacement of the EBD is $5.08 \mathrm{~mm}$. When the vacuum degree is $0.4 \mathrm{~atm}$, the second peak displacement of the EBD is $4.92 \mathrm{~mm}$. Here, the second peak displacement of the EBD at 0.2 atm is slightly greater than that at $0.4 \mathrm{~atm}$. The reason is that when the vacuum degree inside the explosion vessel is reduced to $0.2 \mathrm{~atm}$, the air becomes relatively thin, and the overpressure of shock waves caused by air is relatively small. However, the shock wave overpressure at $0.2 \mathrm{~atm}$ caused by the detonation product is 1.3 times higher than that at $0.4 \mathrm{~atm}$. The second peak on the displacement time history curve is caused by the detonation product's shock wave overpressure.

In this section, the dynamic response of the EBD is analyzed at $0.2 \mathrm{~atm}, 0.4 \mathrm{~atm}, 0.6 \mathrm{~atm}, 0.8 \mathrm{~atm}$, and $1 \mathrm{~atm}$. After a comparative study, it is found that reducing the ambient pressure helps improve the blast-resistance capacity of the structure. The maximum von Mises stress contour of the EBD at $1 \mathrm{~atm}$ is given in Figure 16. Compared with Figure 13, the 
TABle 5: Peak displacement, von Mises stress, and effective plastic strain.

\begin{tabular}{lccc}
\hline Type & Peak displacement $(\mathrm{mm})$ & Maximum von Mises stress $(\mathrm{MPa})$ & Maximum effective plastic strain (\%) \\
\hline FBD & 75.7 & 434.7 & 0.14 \\
RFBD1 & 71.8 & 453.4 & 0.58 \\
RFBD2 & 71.2 & 430.6 & 0.47 \\
RFBD3 & 67.5 & 455.4 & 0.49 \\
RFBD4 & 69.6 & 449.5 & 0.48 \\
RFBD5 & 66.8 & 454.2 & 0.52 \\
EBD & 5.1 & 437.6 & 0.11 \\
\hline
\end{tabular}

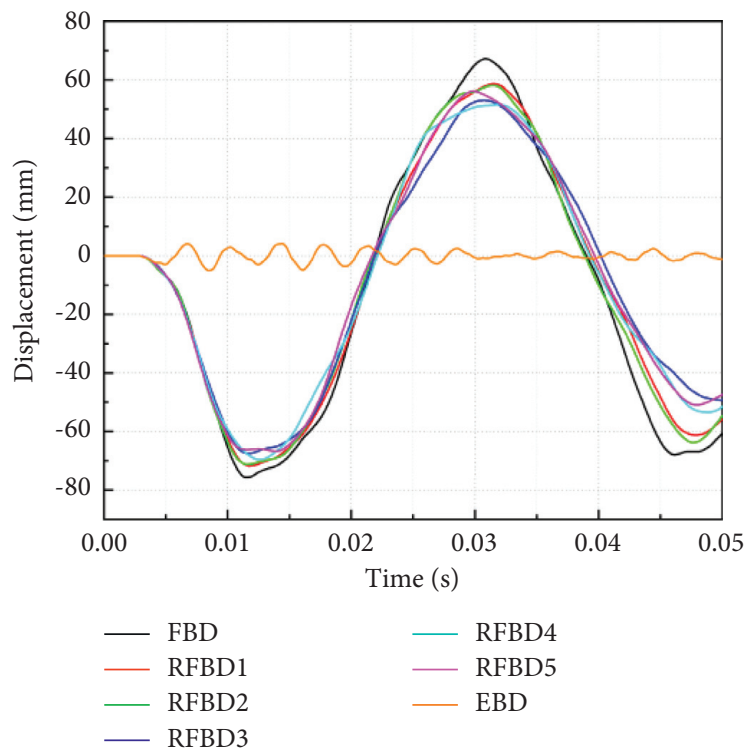

Figure 10: Displacement time history curves of different blast-resistant doors.

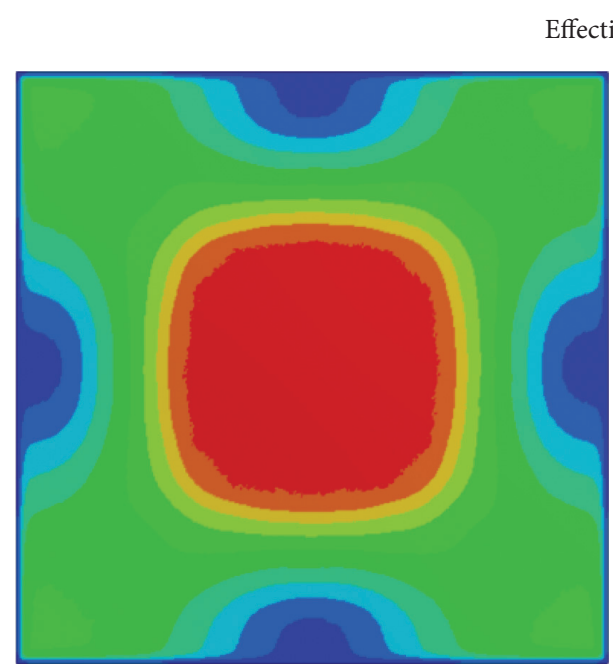

(a)

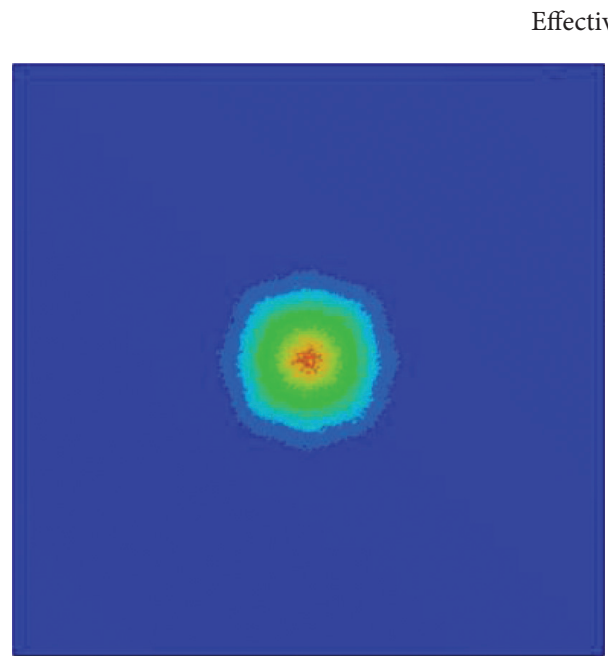

(b)

FIGURE 11: (a) von Mises stress and (b) effective plastic strain of the FBD.

EBD generates higher stress at the joint between the elliptical panel and the arc support plate and along the joint between the triangle support plate and the arc support plate. It shows the transfer process of explosive load on the EBD. That is to say, and the explosive load is first transferred from the elliptical panel to the arc support plate, then from the arc support plate to the triangle support plate, and finally to the support. Figure 17 shows the maximum effective plastic strain contour of the EBD at $1 \mathrm{~atm}$. It can be seen from Figure 17 that with the increase of explosive load, the EBD produces great plastic 


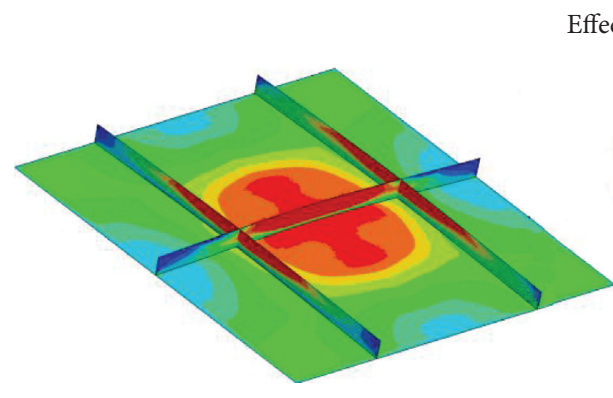

(a)
Effective Stress (v-m)

$4.542 \mathrm{e}+08$
$4.088 \mathrm{e}+08$
$3.635 \mathrm{e}+08$
$3.181 \mathrm{e}+08$
$2.728 \mathrm{e}+08$
$2.274 \mathrm{e}+08$
$1.820 \mathrm{e}+08$
$1.367 \mathrm{e}+08$
$9.132 \mathrm{e}+07$
$4.596 \mathrm{e}+07$
$6.024 \mathrm{e}+05$

$6.024 \mathrm{e}+05$

Figure 12: (a) von Mises stress and (b) effective plastic strain of the RFBD5.

Effective Plastic Strain

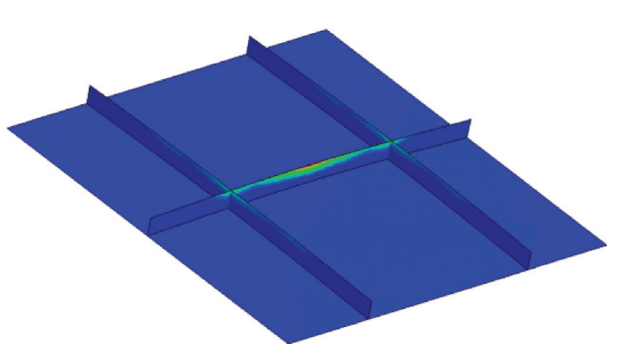

5.237e- 03

$4.714 \mathrm{e}-03$

$4.190 \mathrm{e}-03$

$3.666 \mathrm{e}-03$

$3.142 \mathrm{e}-03$

$2.619 \mathrm{e}-03$

$2.095 \mathrm{e}-03$

$1.571 \mathrm{e}-03$

$1.047 \mathrm{e}-03$

$5.237 \mathrm{e}-04$

$0.000 \mathrm{e}+00$

(b)

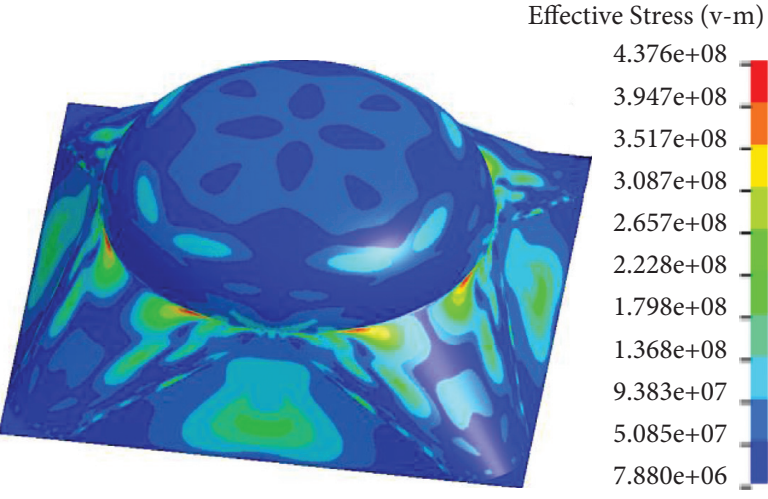

(a)

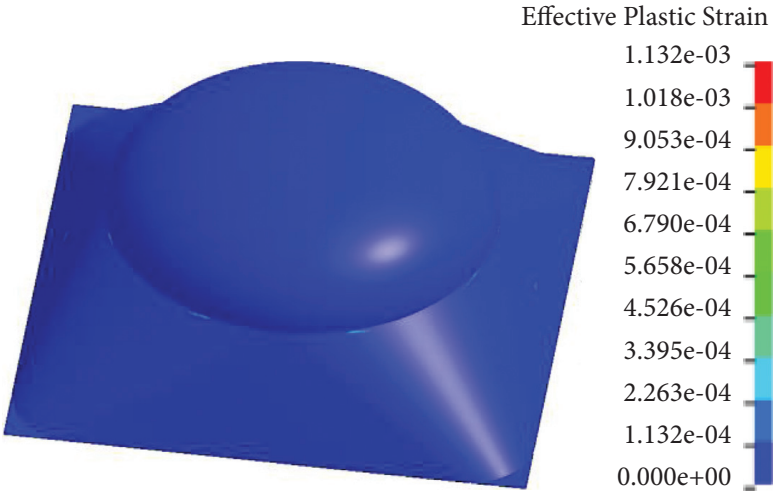

(b)

Figure 13: (a) von Mises stress and (b) effective plastic strain of the EBD.

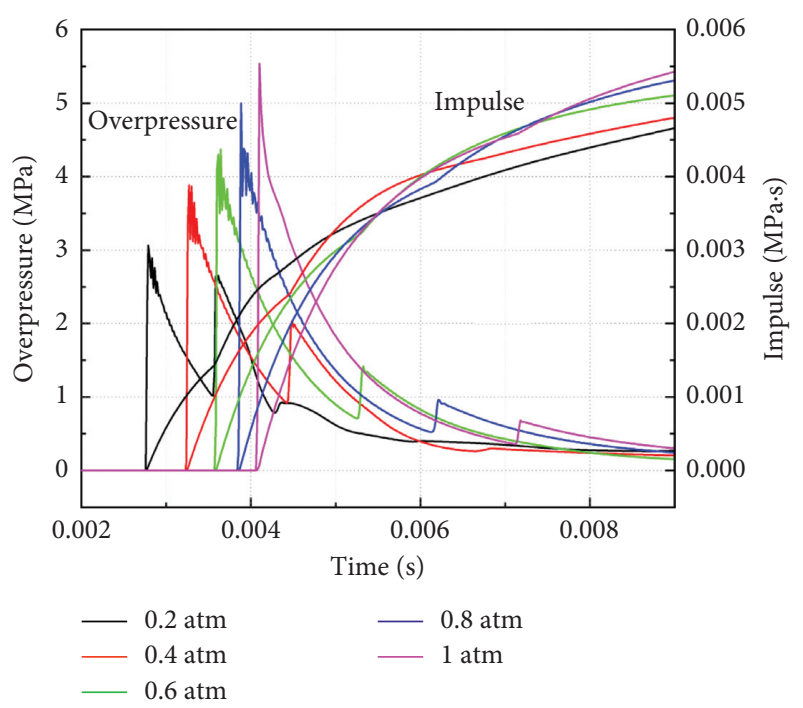

Figure 14: Explosive load under different vacuum degrees.

deformation in the high-stress area of the structural joint. Furthermore, the EBD also produces great plastic deformation in the middle of the triangle support plate. Therefore, these places with large plastic deformation should be strengthened in the design of the EBD.
4.2. Effect of Explosive Quantity. The vacuum degree in the explosion vessel is kept unchanged, which is $0.2 \mathrm{~atm}$. The explosive load acting on the blast-resistant door with $200 \mathrm{~kg}$, $400 \mathrm{~kg}, 600 \mathrm{~kg}$, and $800 \mathrm{~kg}$ charges are calculated by changing the number of explosives. When the explosive quantity is $600 \mathrm{~kg}$, the dynamic response of the EBD has been calculated in Section 3. Figure 18 shows the explosive load under different explosive quantities. It can be seen in Figure 18 and Table 7 that when the explosive quantity increases from $200 \mathrm{~kg}$ to $800 \mathrm{~kg}$, the peak overpressure increases from 1.57 $\mathrm{MPa}$ to $4.33 \mathrm{MPa}$, which increases by 2.76 times, while the action time of the explosive load decreases slightly. The mid-span displacement time history curve of the EBD under different explosive quantities is shown in Figure 19. As can be seen from Figure 19, when the explosive quantity decreases from $800 \mathrm{~kg}$ to $200 \mathrm{~kg}$, the first peak of the EBD's displacement decreases from $3.76 \mathrm{~mm}$ to $1.10 \mathrm{~mm}$, reducing by $70.7 \%$; the second peak of the EBD's displacement decreases from $6.09 \mathrm{~mm}$ to $1.85 \mathrm{~mm}$, reducing by $69.6 \%$. It indicates that reducing the explosive quantity can improve the blast-resistance capacity of the EBD. Table 7 gives the peak displacement, the maximum von Mises stress, and the maximum effective plastic strain of the EBD under different explosive quantities. It can be seen from Table 7 that when the explosive quantity is $200 \mathrm{~kg}$, the $\mathrm{EBD}$ is in a state of 
TABle 6: Displacement, von Mises stress, and effective plastic strain of the EBD under different vacuum degrees.

\begin{tabular}{|c|c|c|c|c|c|c|}
\hline \multirow{2}{*}{$\begin{array}{l}\text { Vacuum degree } \\
(\text { atm) }\end{array}$} & \multicolumn{2}{|c|}{ Load (MPa) } & \multicolumn{2}{|c|}{ Displacement $(\mathrm{mm})$} & \multirow{2}{*}{$\begin{array}{l}\text { Maximum von Mises stress } \\
(\mathrm{MPa})\end{array}$} & \multirow{2}{*}{$\begin{array}{c}\text { Maximum effective plastic strain } \\
(\%)\end{array}$} \\
\hline & Air & $\begin{array}{c}\text { Detonation } \\
\text { product }\end{array}$ & $\begin{array}{l}\text { First } \\
\text { peak }\end{array}$ & $\begin{array}{l}\text { Second } \\
\text { peak }\end{array}$ & & \\
\hline 0.2 & 3.07 & 2.65 & 3.03 & 5.08 & 437.6 & 0.11 \\
\hline 0.4 & 3.88 & 2.04 & 3.27 & 4.92 & 456.6 & 0.22 \\
\hline 0.6 & 4.37 & 1.42 & 3.32 & 5.36 & 489.4 & 0.54 \\
\hline 0.8 & 5.00 & 0.96 & 3.51 & 6.62 & 503.7 & 0.93 \\
\hline 1 & 5.54 & 0.68 & 3.79 & 7.45 & 510.3 & 1.03 \\
\hline
\end{tabular}

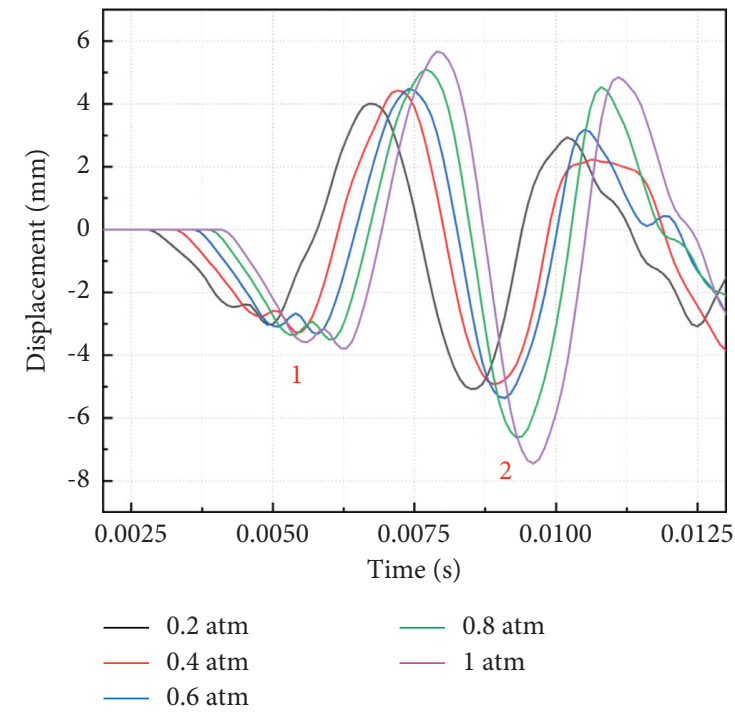

Figure 15: The mid-span displacement time history curve of the EBD under different vacuum degrees.

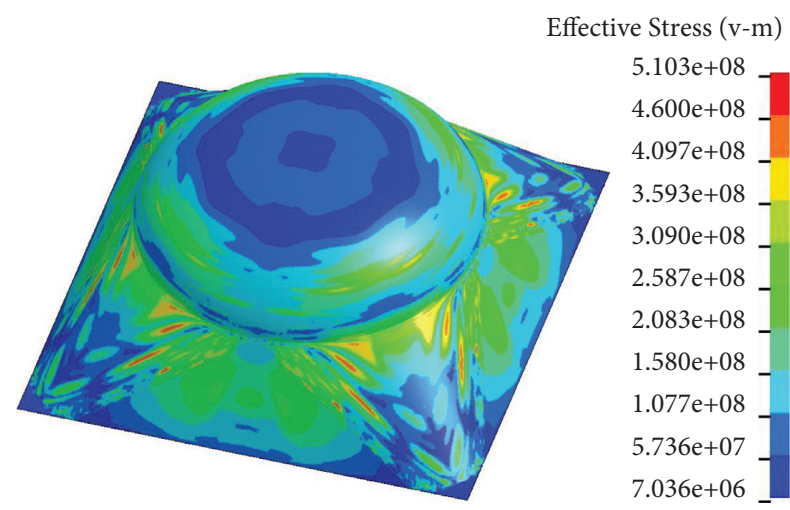

Figure 16: The maximum von Mises stress contour of the EBD at $1 \mathrm{~atm}$.

perfect elasticity deformation. When the explosive quantity is $800 \mathrm{~kg}$, the maximum von Mises stress and the maximum effective plastic strain of the EBD are $456.8 \mathrm{MPa}$ and $0.24 \%$, respectively. Although the explosion vessel's maximum design charge is $600 \mathrm{~kg}$ ANFO explosive, the EBD is still in a small plastic deformation state when the explosive quantity is $800 \mathrm{~kg}$. Its plastic strain is far less than the fracture strain of Q355 steel, so the EBD will not fracture suddenly. Taken together, during the explosive working, the explosive load

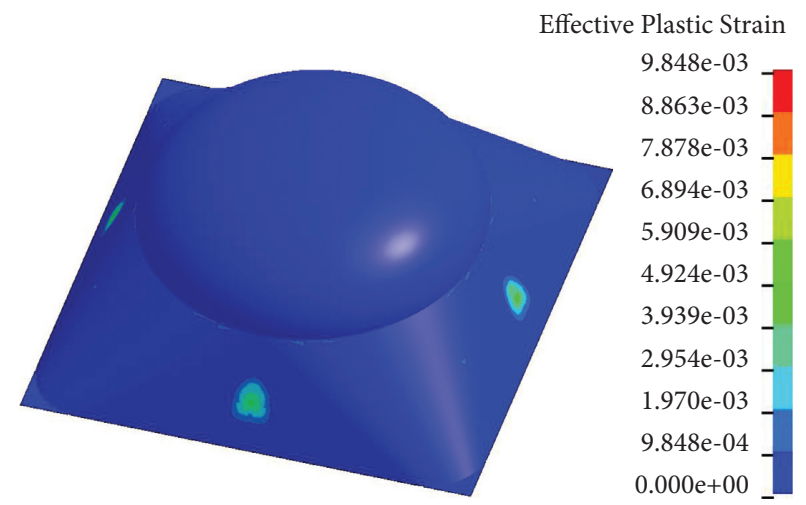

FIGURE 17: The maximum effective plastic strain contour of the EBD at $1 \mathrm{~atm}$.

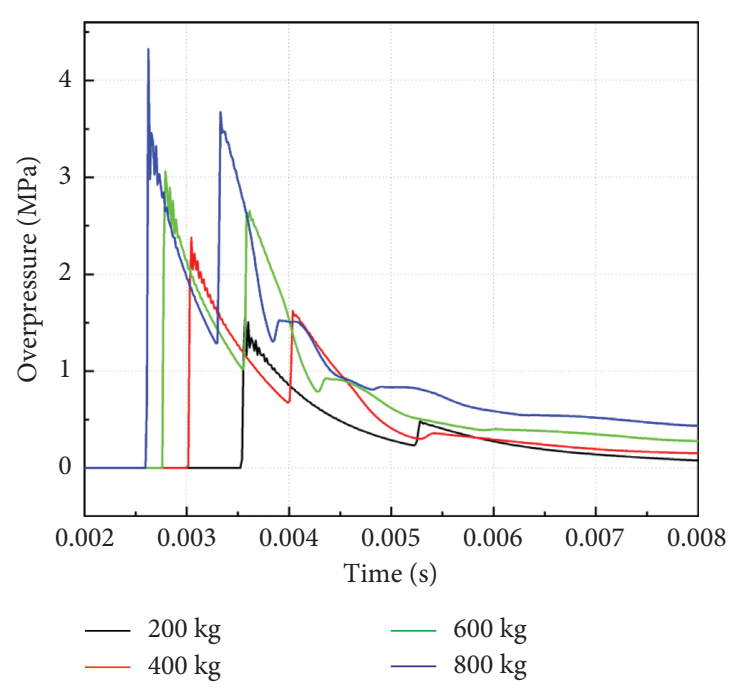

FIGURE 18: Explosive load under different explosive quantities.

acting on the blast-resistant door can be reduced by regulating the explosive quantity. In this way, it can ensure that the EBD can work under the safe explosive quantity.

4.3. Effect of Diameter Ratio. In this section, the blast-resistance capability of the EBD with four different diameter ratios of 1:0.25, 1:0.5, 1:0.75, and 1:1 is analyzed. The elliptical panel's major axis diameter is always $3,000 \mathrm{~mm}$, and different diameter ratios are achieved by changing the minor axis diameter. When the diameter ratio is $1: 0.25,1: 0.5,1$ : 
TABLe 7: Displacement, von Mises stress, and effective plastic strain of the EBD under the different explosive quantities.

\begin{tabular}{lcccccc}
\hline \multirow{2}{*}{$\begin{array}{l}\text { Explosive quantity } \\
(\mathrm{kg})\end{array}$} & $\begin{array}{c}\text { Load } \\
\text { Peak overpressure } \\
(\mathrm{MPa})\end{array}$ & $\begin{array}{c}\text { Peak displacement } \\
(\mathrm{mm})\end{array}$ & $\begin{array}{c}\text { Maximum von Mises } \\
(\mathrm{ms})\end{array}$ & $\begin{array}{c}\text { First } \\
\text { peak }\end{array}$ & $\begin{array}{c}\text { Second } \\
\text { peak }\end{array}$ & $\begin{array}{c}\text { Maximum effective plastic } \\
\text { stress (MPa) }\end{array}$ \\
\hline 200 & 1.57 & 13.0 & 1.10 & 1.85 & 317.9 & 0 \\
400 & 2.38 & 11.0 & 2.17 & 3.55 & 412.7 & 0.02 \\
600 & 3.07 & 10.5 & 3.03 & 5.08 & 437.6 & 0.11 \\
800 & 4.33 & 10.0 & 3.76 & 6.09 & 456.8 & 0.24 \\
\hline
\end{tabular}

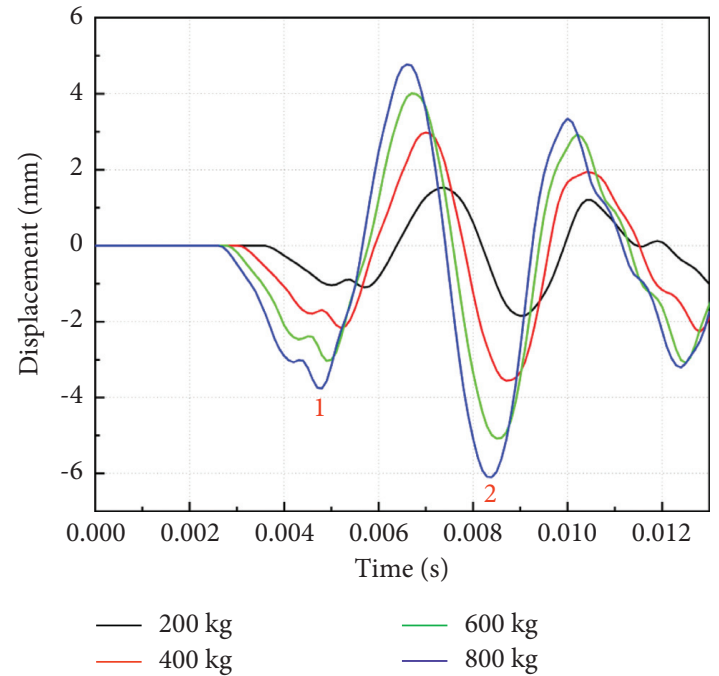

FIGURE 19: The mid-span displacement time history curve of the EBD under the different explosive quantities.

0.75 , and 1:1, then the elliptical panel's corresponding minor axis diameter is $750 \mathrm{~mm}, 1,500 \mathrm{~mm}, 2,250 \mathrm{~mm}$, and $3,000 \mathrm{~mm}$, respectively. In this paper, the EBD's mass with different diameter ratios is kept equal by adjusting the steel plate's thickness. The thickness dimensions are shown in Table 8. The EBD with a diameter ratio of 1:0.5 has been calculated in Section 3. The mid-span displacement time history curve of the EBD with different diameter ratios is shown in Figure 20. Table 8 gives the peak displacement, the maximum von Mises stress, and the maximum effective plastic strain of the EBD with different diameter ratios. It can be seen in Figure 20 and Table 8 that by changing the EBD's diameter ratio (i.e., increasing minor axis diameter), the mid-span peak displacement of the EBD gradually decreases, and the vibration period of the displacement curve also gradually decreases accordingly. It indicates that increasing the diameter of the EBD's minor axis can improve their flexural rigidity. When the diameter ratio is $1: 0.25$, the maximum von Mises stress and the maximum effective plastic strain of the EBD are the smallest among the four structures, but the peak displacements are the largest. When the minor axis diameter of the EBD is greater than $750 \mathrm{~mm}$, the maximum von Mises stress and the maximum effective plastic strain of the EBD with the diameter ratio of 1:0.75 are both less than those with the diameter ratio of 1:0.5 and 1:1. In summary, the optimum diameter ratio of the EBD proposed in this paper is 1:0.75.
TABLE 8: Displacement, von Mises stress, and effective plastic strain of the EBD with different diameter ratios.

\begin{tabular}{lcccc}
\hline $\begin{array}{l}\text { Diameter } \\
\text { ratio }\end{array}$ & $\begin{array}{c}\text { Thickness } \\
(\mathrm{mm})\end{array}$ & $\begin{array}{c}\text { Peak } \\
\text { displacement } \\
(\mathrm{mm})\end{array}$ & $\begin{array}{c}\text { Maximum } \\
\text { von Mises } \\
\text { stress } \\
(\mathrm{MPa})\end{array}$ & $\begin{array}{c}\text { Maximum } \\
\text { effective } \\
\text { plastic } \\
\text { strain }\end{array}$ \\
\hline $1: 0.25$ & 53.9 & 9.44 & 397.3 & $5.93 \times 10^{-6}$ \\
$1: 0.5$ & 50.0 & 5.08 & 437.6 & $1.13 \times 10^{-3}$ \\
$1: 0.75$ & 46.0 & 2.85 & 424.3 & $5.33 \times 10^{-4}$ \\
$1: 1$ & 42.3 & 2.76 & 454.1 & $2.42 \times 10^{-3}$ \\
\hline
\end{tabular}

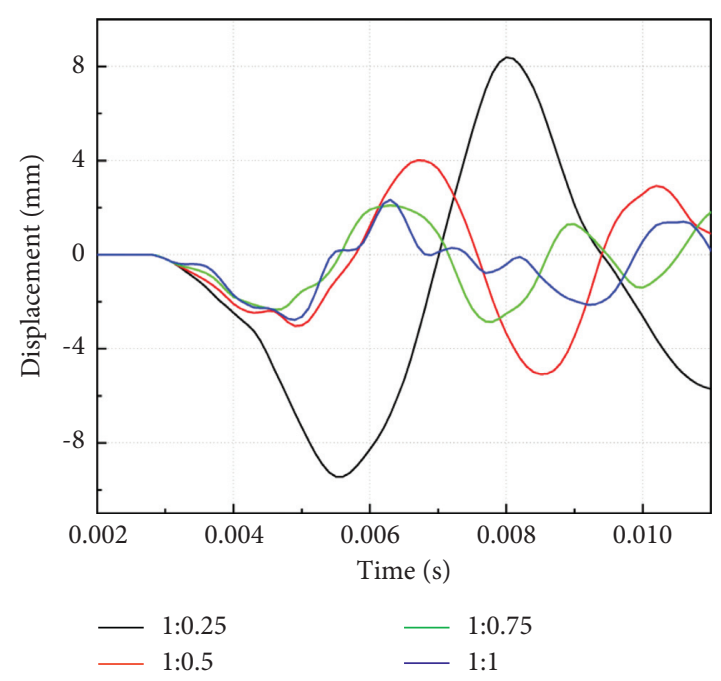

FIGURE 20: The mid-span displacement time history curve of the EBD with different diameter ratios.

\section{Conclusions}

This paper proposes an elliptical blast-resistant door with the combined structure for the large vacuum explosion container consisting of an elliptical panel, four arc support plates, and four triangle support plates. The following conclusions are drawn from the numerical calculations:

(1) The decoupling method is reasonable for solving the dynamic response of the large vacuum explosion container's blast-resistant door. It can significantly reduce the calculation amount of the project and provide a reference for similar engineering problems. 
(2) The peak displacement of the elliptical blast-resistant door with the combined structure is $93.3 \%$ less than that of the flat blast-resistant door and $92.4 \%$ less than that of the reinforced flat blast-resistant door with the smallest peak displacement (RFBD5). By analyzing the stress and strain, the maximum von Mises stress and the maximum effective plastic strain of the elliptical blast-resistant door with the combined structure are smaller than those of the flat plate blast-resistant door and the reinforced flat blastresistant door. It indicates that the blast-resistance capacity of the elliptical blast-resistant door with the combined structure proposed in this paper is better than that of the traditional blast-resistant door.

(3) The parametric analysis shows that the blast-resistance capacity of the elliptical blast-resistant door with the combined structure can be improved effectively by reducing the vacuum degree in the explosion vessel and the number of explosives during the explosion working. During the production of explosion working, the vacuum degree should be controlled not greater than $0.2 \mathrm{~atm}$, and the explosive quantity should not be greater than $600 \mathrm{~kg}$.

(4) By analyzing the peak displacement, the maximum von Mises stress, and the maximum effective plastic strain, it is determined that the optimum diameter ratio of the elliptical blast-resistant door with the combined structure is $1: 0.75$.

\section{Data Availability}

The data used to support the findings of this study are included within the article.

\section{Conflicts of Interest}

The authors declare that they have no conflicts of interest.

\section{Acknowledgments}

This work was supported by the National Natural Science Foundation of China (Nos. 12172084, 12072067, and 11672067).

\section{References}

[1] J. S. Rinehart and J. Pearson, Explosive Working of Metals, Pergamon Press, New York, NY, USA, 1963.

[2] A. Maranda, J. Nowaczewski, and A. Przetakiewicz, "Explosive strengthening of the surface layer in St72P steel rails," Journal of Materials Processing Technology, vol. 34, no. 1-4, pp. 241-245, 1992.

[3] Z. Tong, Z. M. Shi, S. J. Tong, D. W. Wang, and P. F. Li, "Surface nanocrystallization, austenization and hardening of medium carbon steel by an explosive impact technique," Surface and Coatings Technology, vol. 251, pp. 293-299, 2014.

[4] H. Wang, Z. Shi, X. Yaer, Z. Tong, and Z. Du, "High mechanical performance of AISI304 stainless steel plate by surface nanocrystallization and microstructural evolution during the explosive impact treatment," Journal of materials research and technology, vol. 8, no. 1, pp. 609-614, 2019.

[5] B. Crossland, Explosive Welding of Metals and its Application, Clarendon Press, Oxford, England, 1982.

[6] Y. Wang, X. Li, X. Wang, and H. Yan, "Fabrication of a thick copper-stainless steel clad plate for nuclear fusion equipment by explosive welding," Fusion Engineering and Design, vol. 137, pp. 91-96, 2018.

[7] X.-y. Zeng, X.-j. Li, X. Chen, X.-h. Wang, and H.-h. Yan, "Numerical and experimental studies on the explosive welding of plates with different initial strength," Welding in the World, vol. 63, 2019.

[8] X. Chen, X. Li, X. Wang, H. Yan, K. Li, and X. Zeng, "Bonding mechanism of explosive compaction-welding sintering," Journal of Manufacturing Processes, vol. 46, pp. 1-15, 2019.

[9] S. Vorozhtsov, A. Vorozhtsov, O. Kudryashova, I. Zhukov, and V. Promakhov, "Structural and mechanical properties of aluminium-based composites processed by explosive compaction," Powder Technology, vol. 313, pp. 251-259, 2017.

[10] A. Y. Cui, F. Y. Hu, H. K. Wei, H. D. Liu, Z. Wang, and $\mathrm{X}$. L. Dong, "Research on rapid shaped-charge cutting technology of aircraft damaged thin-wall structures," Strength of Materials, vol. 48, no. 1, pp. 58-62, 2016.

[11] N. Narimanzadeh, A. Darvizeh, M. Darvizeh, and H. Gharababaei, "Modelling of explosive cutting process of plates using GMDH-type neural network and singular value decomposition," Journal of Materials Processing Technology, vol. 128, no. 128, pp. 80-87, 2002.

[12] H. Wegener, H. U. Freund, and S. Schumann, "Explosive cutting of thick-walled steel pipes in the reactor HDR," Nuclear Engineering and Design, vol. 118, no. 1, pp. 87-97, 1990.

[13] X. Li, X. Li, X. Wang, X. Pan, and H. Yan, "Characterization of carbon-encapsulated permalloy nanoparticles prepared through detonation," Materials Research Express, vol. 4, no. 7, Article ID 075024, 2017.

[14] K. V. Volkov, V. V. Danilenko, and V. I. Elin, "Synthesis of diamond from the carbon in the detonation products of explosives," Combustion, Explosion and Shock Waves, vol. 26, no. 3, pp. 366-368, 1990.

[15] Q. Xiaoyong, The Study on Large Scale Hemispherical ShockWaves Trap Structure for Explosive Welding, Dalian University of Technology, Dalin, China, 2008.

[16] X. Luo, X. Qian, H. Zhao, and P. Huang, "Simulation analysis on structure safety of refuge chamber door under explosion load," Procedia Engineering, vol. 45, pp. 923-929, 2012.

[17] W. Chen and H. Hao, "Numerical study of a new multi-arch double-layered blast-resistance door panel," International Journal of Impact Engineering, vol. 43, pp. 16-28, 2012.

[18] C. G. Koh, K. K. Ang, and P. F. Chan, "Dynamic analysis of shell structures with application to blast resistant doors," Shock and Vibration, vol. 10, no. 4, pp. 269-279, 2003.

[19] G. Dong, L. Jinbo, and Z. Xiaobo, "Resistance parameters analysis and dynamic response for a steel blast door subjected to blast loading," Journal of Vibration and Shock, vol. 32, no. 03, pp. 134-140+156, 2013.

[20] R. P. Mcbean, Analysis of Stiffened Plates by the Finite Element Method, p. 164, Stanford University, Stanford, CA, USA, 1968.

[21] M. M. Alinia and S. H. Moosavi, "A parametric study on the longitudinal stiffeners of web panels," Thin-Walled Structures, vol. 46, no. 11, pp. 1213-1223, 2008.

[22] E. Maiorana, C. Pellegrino, and C. Modena, "Influence of longitudinal stiffeners on elastic stability of girder webs," 
Journal of Constructional Steel Research, vol. 67, no. 1, pp. 51-64, 2011.

[23] Y. Pan and L. A. Louca, "Experimental and numerical studies on the response of stiffened plates subjected to gas explosions," Journal of Constructional Steel Research, vol. 52, no. 2, pp. 171-193, 1999.

[24] P. R. Sahoo and M. Barik, "Free vibration analysis of stiffened plates," Journal of Vibration Engineering \& Technologies, vol. $8,2020$.

[25] Z. Boyi, Z. Dongxian, S. Jian, and W. Wei, "Numerical simulation on dynamic response of blast-resistant door with built-in aluminum matrix syntactic foam," Acta Armamentarii, vol. 35, no. S2, pp. 263-267, 2014.

[26] Z. Zhao, B. Zhang, F. Jin, J. Zhou, H. Chen, and H. Fan, "BFRP reinforcing hierarchical stiffened SMC protective structure," Composites Part B: Engineering, vol. 168, pp. 195-203, 2019.

[27] Z. Zhao, B. Zhang, J. Zhou et al., "Quasi-far-field blast responses of hierarchical orthogrid-stiffened sheet molding compound (SMC) protective door structures," Engineering Structures, vol. 168, pp. 431-446, 2018.

[28] W. E. Baker, P. A. Cox, P. S. Westine, J. J. Kulesz, and R. A. Strehlow, Explosion Hazards and Evaluation, Elsevier Scientific Pub. Co, Amsterdam, Netherlands, 1983.

[29] P. C. Chan and H. H. Klein, "A study of blast effects inside an enclosure," Journal of Fluids Engineering, vol. 116, no. 3, pp. 181-189, 1994.

[30] C. Geretto, S. Chung Kim Yuen, and G. N. Nurick, "An experimental study of the effects of degrees of confinement on the response of square mild steel plates subjected to blast loading," International Journal of Impact Engineering, vol. 79, no. may, pp. 32-44, 2015

[31] W. Olson, I. Patterson, and J. Williams, "The effect of atmospheric pressure on the reflected impulse from air blast waves," Army Ballistic Research Lab Aberdeen Proving Ground.MD, 1960.

[32] R. G. Sachs, "The dependence of blast on ambient pressure and temperature," Army Ballistic Research Lab Aberdeen Proving Ground, MD, 1944.

[33] R. L. Veldman, M. W. Nansteel, C. C.-T. Chen, and B. A. Toner, "The effect of ambient pressure on blast reflected impulse and overpressure," Experimental Techniques, vol. 41, no. 3, pp. 227-236, 2017.

[34] J. Shin, A. S. Whittaker, D. Cormie, and W. Wilkinson, "Numerical modeling of close-in detonations of high explosives," Engineering Structures, vol. 81, pp. 88-97, 2014.

[35] L. Davis and L. Hill, ANFO cylinder Tests, AIP Conference Proceedings, pp. 165-168, American Institute of Physics, College park, MD, USA, 2002.

[36] C. E. Anderson, W. E. Baker, D. K. Wauters, and B. L. Morris, "Quasi-static pressure, duration, and impulse for explosions (e.g. HE) in structures," International Journal of Mechanical Sciences, vol. 25, no. 6, pp. 455-464, 1983.

[37] W.-K. Sun, L.-W. Zhang, and K. M. Liew, "A smoothed particle hydrodynamics-peridynamics coupling strategy for modeling fluid-structure interaction problems," Computer Methods in Applied Mechanics and Engineering, vol. 371, Article ID 113298, 2020.

[38] S. C. White, G. Raju, and P. M. Weaver, "Initial post-buckling of variable-stiffness curved panels," Journal of the Mechanics and Physics of Solids, vol. 71, pp. 132-155, 2014.

[39] D. M. Li, C. A. Featherston, and Z. Wu, "An element-free study of variable stiffness composite plates with cutouts for enhanced buckling and post-buckling performance,"
Computer Methods in Applied Mechanics and Engineering, vol. 371, Article ID 113314, 2020.

[40] K. Liew and T. Teo, "Modeling via differential quadrature method: three-dimensional solutions for rectangular plates," Computer Methods in Applied Mechanics and Engineering, vol. 159, no. 3-4, pp. 369-381, 1998.

[41] R. Barauskas and A. Abraitiene, "Computational analysis of impact of a bullet against the multilayer fabrics in LS-DYNA," International Journal of Impact Engineering, vol. 34, no. 7, pp. 1286-1305, 2007.

[42] W. Rust and K. Schweizerhof, "Finite element limit load analysis of thin-walled structures by ANSYS (implicit), LSDYNA (explicit) and in combination," Thin-Walled Structures, vol. 41, no. 2-3, pp. 227-244, 2003.

[43] B. A. Gama and J. W. Gillespie, "Finite element modeling of impact, damage evolution and penetration of thick-section composites," International Journal of Impact Engineering, vol. 38, no. 4, pp. 181-197, 2011.

[44] Z. Yu, Research on Dynamic Constitutive Relationship of Q355B Steel Based on Johnson-Cook Model, Harbin University of Science and Technology, Harbin, China, 2019.

[45] G. R. Johnson and W. H. Cook, "Fracture characteristics of three metals subjected to various strains, strain rates, temperatures and pressures," Engineering Fracture Mechanics, vol. 21, no. 1, pp. 31-48, 1985. 